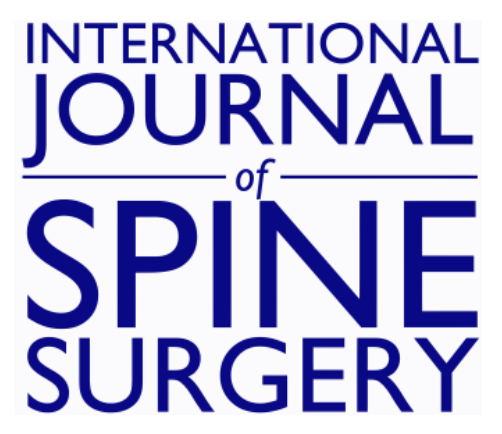

\title{
Elastomeric Lumbar Total Disc Replacement: Clinical and Radiological Results With Minimum 84 Months Follow-Up
}

LUIZ PIMENTA, LUIS MARCHI, LEONARDO OLIVEIRA, JOES NOGUEIRA-NETO,
ETEVALDO COUTINHO and RODRIGO AMARAL

Int J Spine Surg 2018, 12 (1) 49-57

doi: https://doi.org/10.14444/5009

http://ijssurgery.com/content/12/1/49

This information is current as of April 26, 2023.

Email Alerts Receive free email-alerts when new articles cite this article. Sign up at:

http://ijssurgery.com/alerts

The International Journal of Spine Surgery

2397 Waterbury Circle, Suite 1,

Aurora, IL 60504, Phone: +1-630-375-1432 


\title{
Elastomeric Lumbar Total Disc Replacement: Clinical and Radiological Results With Minimum 84 Months Follow-Up
}

\author{
LUIZ PIMENTA, MD, PhD,${ }^{1,2}$ LUIS MARCHI, PhD,${ }^{1}$ LEONARDO OLIVEIRA, BSc, ${ }^{1}$ JOES NOGUEIRA- \\ NETO, PhD,${ }^{1}$ ETEVALDO COUTINHO, MD,${ }^{1}$ RODRIGO AMARAL, MD ${ }^{1}$ \\ ${ }^{1}$ Instituto de Patologia da Coluna, São Paulo, Brazil, ${ }^{2}$ University of California San Diego, San Diego, California
}

\begin{abstract}
Background: Total lumbar disc replacement (TDR) devices have been designed to maintain motion, but both biomechanical and clinical data have indicated that a more controlled motion and additional load absorption in TDR would be beneficial. This work analyzed long-term results of an elastomeric disc (Physio-L) for degenerative lumbar conditions.

Material and Methods: This was a prospective, noncomparative, single-center clinical and radiological study. A total of 15 patients with predominant low back pain due degenerative disc disease received anterior total disc replacement with a Physio-L disc. Clinical outcomes were assessed both with a visual analog scale for pain and Oswestry Disability Index questionnaires. Radiological outcomes included implant failure, range of motion (ROM), facet degeneration, and adjacent level disease. Complication and reoperation rates were also recorded. The cases were assessed with a minimum follow-up of 84 months.
\end{abstract}

Results: A total of 15 patients were enrolled (20 TDRs) - 10 single-level cases (L5S1) and 5 two-level cases (L4L5/ L5S1). After 84 months, clinical outcomes scores still demonstrated significant improvement compared with baseline $(P<$ .001). Mean visual analog scale scores dropped from 7.1 to 2.9, and the Oswestry Disability Index improved from 50 to 16 . No disc has experienced migration or breakage. The average range of motion value went from a baseline of $12.0^{\circ}$ to $13.3^{\circ}$ at 12 months, and at the final follow-up it decreased to $9.9^{\circ}$. Regarding the double-level cases, 3 of $5(60 \%)$ had adverse events; just 1 single-level $(10 \%)$ had adverse events. At final follow-up, radiological signs of facet degeneration were present in 7 of 15 patients $(47 \%)$ but with only 1 of $15(6.7 \%)$ symptomatic. Two patients $(13 \%)$ required surgery at the adjacent level. At the 84-month follow-up, 16 of 18 prostheses (89\%) were still active ( 2 revised to fusion and 2 were lost to follow-up).

Conclusion: The long-term follow-up data shows satisfactory clinical results for the use of Physio-L elastomeric TDR in the treatment of degenerative disc disease. Studies with bigger cohorts are needed to replicate results and add new information regarding other details.

\section{Cervical Spine}

Keywords: spine, intervertebral disc degeneration/surgery, arthroplasty, artificial disc, disc replacement, lumbar vertebrae/surgery

\section{INTRODUCTION}

The intervertebral disc absorbs about $80 \%$ of spinal loads and allows controlled movement between these vertebrae. ${ }^{1}$ This structure is formed by the nucleus pulposus and the annulus fibrosus, an external fibrous ring. ${ }^{2}$ During the aging process, the intervertebral disc tends to become less hydrated, losing flexibility, height, and load-absorption capability. ${ }^{3}$ This process is named degenerative disc disease (DDD), in which both biomechanical and molecular changes are involved, and it can evolve with or without pain. ${ }^{4}$

One of the surgical treatment options for DDD is discectomy followed by interbody fusion. There are many surgical techniques that achieve fusion, such as transforaminal lumbar interbody fusion, anterior lumbar interbody fusion, and lateral lumbar interbody fusion, among others. ${ }^{5}$ Whereas fusion has historical good results in clinical improvement and pain relief, there are some limitations regarding this option. In addition to the possibility of failure to achieve fusion, the biomechanical alterations followed by the arthrodesis can disturb both motion and load vectors at the adjacent segment levels, changes that can accelerate the natural history of degenerative cascade and may cause adjacent level degeneration (ALD). Thus, the use of nonfusion options has evolved not only in the spine, ${ }^{6-9}$ but also in the hip ${ }^{10}$ and knee. ${ }^{11}$

Total lumbar disc replacement (TDR) is a surgical option for the treatment of DDD that fails conservative therapy. Differently from fusion, the 


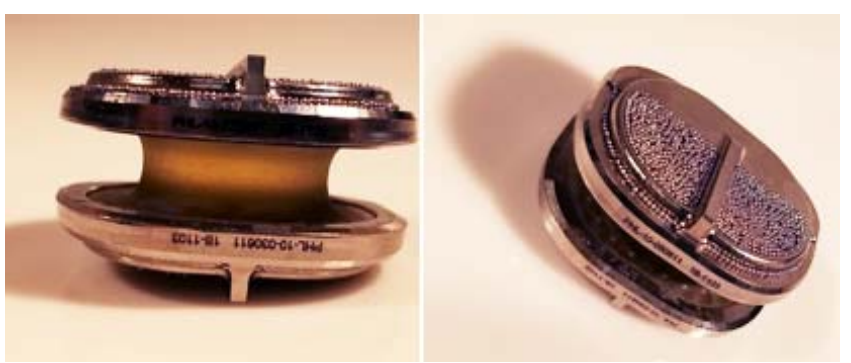

Figure 1. Physio-L elastomeric prosthesis for lumbar total disc replacement.

artificial disc allows movement in the operated level, attempting to mimic the biomechanical properties of a healthy spine. ${ }^{6}$ In this manner, TDR can result in a lower probability to degenerate the adjacent levels in comparison to fusion. ${ }^{12,13}$ To achieve its purpose, TDR is not indicated for cases with advanced DDD, facet arthroplasty, spondylolisthesis, instability, or bone stenosis. ${ }^{14}$ The artificial disc has evolved over the years to systems more similar to the intact human spine segment, with properties able to control motion and absorb load. Physio-L (K2M Group Holdings, Leesburg, Virginia), is an artificial intervertebral disc implant with a single polycarbonate polyurethane elastomeric core that was developed to improve some limitations of the past generation of lumbar TDR. Therefore, this work aimed to analyze long-term radiological and clinical results of Physio-L TDR for degenerative conditions of the distal lumbar levels.

\section{MATERIALS AND METHODS}

This was a noncomparative, retrospective, singlecenter study with prospective data collection on a case series treated with TDR using the Physio-L artificial disc (Figure 1). The Physio-L is a 1-piece device that uses a core made of polycarbonate polyurethane (elastomeric) attached to 2 titanium end-plates coated with titanium beads.

The same senior spine surgeon selected and operated on all patients included in this work. Discectomy and TDR insertion was performed through a mini-anterior lumbar interbody fusion exposure of the lumbosacral spine. End-plate preparation was performed using contoured bone rasps to closely match the specific dome shape of the metal end-plates. A keel cutter was used to cut the channels on vertebral end-plates for the central keel without violating the anterior cortex. Following end-plate preparation, the artificial disc was inserted as a single unit.

Cases were included between March and August 2007. Criteria for inclusion include patients present- ing with predominant low back pain caused by DDD; failure with nonoperative treatment for a minimum of 6 months; and DDD at 1 or 2 levels between L3-S1 confirmed by clinical presentation, magnetic resonance imaging examination, and discography. Criteria for exclusion include active systemic infection or localized infection near the implant site; previous attempt at fusion/TDR at the intended surgical level; severe DDD (grade $\mathrm{V}$ in Pfirrmann scale ${ }^{15}$ ); isolated radicular compression symptoms due to disc herniation; allergy or sensitivity to implant materials; osteoporosis; lumbar stenosis, facet joints arthritis (grades 3 and 4 in Fujiwara scale ${ }^{16}$ ); osteopenia; pars defects; and instability and/or deformity.

Follow-up was performed at different visits: preoperative; 6 weeks; $3,6,12$, and 24 months; and final follow-up (minimum of 84 months). Clinical and radiographic results were compared with preoperative baseline and short-term data (12/24 months) to evaluate the long-term effect of the use of Physio-L.

Clinical evaluations included physical examination and self-assessed questionnaires: visual analog scale (VAS) for back pain and Oswestry Disability Index (ODI). Minimal clinically important difference (MCID) was used to assess the clinical relevance in the statistical improvement in pain and disability scores. The MCID calculation was used with the standard deviation (SD) as reference. The MCID value was calculated as the preoperative VAS or ODI score minus half SD. ${ }^{17,18}$

Radiological outcomes were assessed with x-rays, and computed tomography or nuclear magnetic resonance included implant condition (subsidence, radiolucency around the end-plates, displacement, migration, and disruption of the core/end-plates), range of motion (ROM), and lordosis at index level. Incidence of adjacent-level degeneration, complications, and reoperations were also recorded.

Statistical analyses included descriptive statistics to characterize baseline variables, and paired $t$ tests were used to determine statistically significant changes from preoperative to follow-up as appropriate. Level of significance was considered .05 .

\section{RESULTS}

\section{Study Population and Follow-Up}

The initial cohort consisted of 15 cases and a total of 20 TDRs. Average age was 37.0 years (range, 2554 years), and the average body mass index was 23.7 
Table 1. Clinical outcomes at minimum 84-month follow-up (final).

\begin{tabular}{|c|c|c|c|c|c|c|c|c|c|c|c|c|c|c|}
\hline \multirow[b]{2}{*}{ Case No. } & \multicolumn{7}{|c|}{ Visual Analog Scale Back Pain } & \multicolumn{7}{|c|}{ Oswestry Disability Index } \\
\hline & Preop & $1.5 \mathrm{mo}$ & 3 mo & $6 \mathrm{mo}$ & $12 \mathrm{mo}$ & $24 \mathrm{mo}$ & Final & Preop & $1.5 \mathrm{mo}$ & 3 mo & $6 \mathrm{mo}$ & $12 \mathrm{mo}$ & 24 mo & Final \\
\hline 2 & 6 & 2 & 1 & 1 & 0 & 0 & 3 & 38 & 26 & 2 & 6 & 2 & 4 & 18 \\
\hline 3 & 8 & 1 & 2 & 1 & 1 & 0 & 2 & 34 & 12 & 10 & 4 & 4 & 6 & 8 \\
\hline 4 & 4 & 0 & 1 & 0 & 0 & 0 & 5 & 42 & 14 & 20 & 0 & 8 & 0 & 22 \\
\hline 5 & 7 & 0 & 0 & 4 & 6 & 6 & 3 & 44 & 8 & 12 & 26 & 48 & 38 & 8 \\
\hline 6 & 5 & 4 & 3 & 2 & 1 & 0 & 0 & 46 & 20 & 8 & 16 & 0 & 0 & 0 \\
\hline 7 & 9 & 0 & 2 & 5 & 1 & 5 & 5 & 44 & 0 & 4 & 4 & 4 & 2 & 20 \\
\hline 8 & 9 & 2 & 1 & 0 & 0 & 0 & 0 & 44 & 28 & 12 & 4 & 8 & 0 & 0 \\
\hline 9 & 8 & 0 & 4 & 1 & 3 & 0 & 0 & 74 & 12 & 26 & 18 & 26 & 0 & 0 \\
\hline 10 & 7 & 5 & 2 & 4 & 2 & 1 & - & 50 & 32 & 28 & 24 & 14 & 6 & - \\
\hline 12 & 7 & 3 & 0 & 3 & 2 & 0 & - & 54 & 12 & 8 & 20 & 6 & 4 & - \\
\hline 13 & 9 & 3 & 4 & 5 & 4 & 3 & 7 & 74 & 48 & 46 & 44 & 36 & 44 & 36 \\
\hline 14 & 7 & 1 & 4 & 2 & 0 & 0 & 3 & 64 & 0 & 10 & 4 & 0 & 4 & 30 \\
\hline 15 & 8 & 5 & 4 & 7 & 3 & 2 & 4 & 62 & 64 & 46 & 38 & 24 & 30 & 34 \\
\hline Mean & 7.2 & 2,0 & 2,2 & 2,7 & 1,8 & 1,3 & 2,9 & 52 & 21 & 18 & 16 & 14 & 11 & 16 \\
\hline SD & 1.5 & 1,9 & 1,5 & 2,2 & 1,8 & 2,1 & 2,3 & 13 & 19 & 15 & 14 & 15 & 16 & 14 \\
\hline $95 \%$ CI & $6.3-8.2$ & $0.9-3.1$ & $1.2-3.1$ & $1.4-4.0$ & $0.7-2.9$ & $0.0-2.6$ & $1.4-4.5$ & $44-59$ & $10-32$ & $9-27$ & $7-25$ & $5-23$ & $1-20$ & $7-25$ \\
\hline$t$ test $(\times \text { preop })^{\mathrm{a}}$ & & $<0.001$ & $<0.001$ & $<0.001$ & $<0.001$ & $<0.001$ & $<0.001$ & & $<0.001$ & $<0.001$ & $<0.001$ & $<0.001$ & $<0.001$ & $<0.001$ \\
\hline
\end{tabular}

${ }^{\mathrm{a}} t$ test $(\times$ preop) indicates values of $P$ regarding follow-up times versus baseline.

$\mathrm{kg} / \mathrm{m}^{2}$ (range, 19.4-28.5 $\mathrm{kg} / \mathrm{m}^{2}$ ). Ten patients received treatment at a single level (L5S1), whereas 5 patients received treatment at 2 levels (L3L4/L5S1 or L4L5/L5S1). From the 15 cases initially enrolled, $13(87 \%)$ were available for analysis in a minimum of 7 years follow-up (data for 7 cases were collected at the 84-month follow-up window, and data for 6 cases were collected at the 96-month follow-up window).

\section{Clinical Outcomes}

Analysis of the self-assessed questionnaires showed a highly significant improvement of pain and disability at postoperative visits in comparison to with baseline levels, including the minimum 7year follow-up (Table $1 ; P<.001$ ). The VAS pain

\section{VAS back pain}

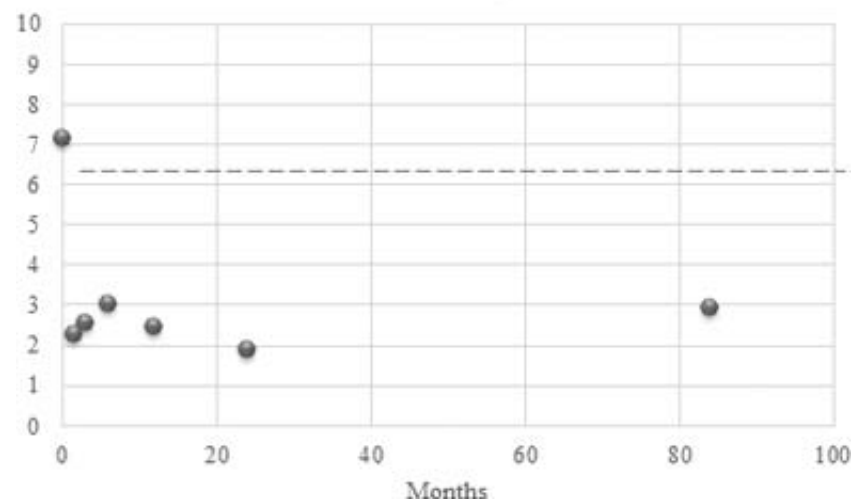

Figure 2. Visual analog scale (VAS) for back pain. The plot shows mean values per follow-up visit. The dotted line represents the minimal clinically important difference value. All postoperative values are statistically different $(P$ $<$.001) from the 0 month point (preoperative). and ODI scores from the last visit were statistically similar to the levels seen in the 12-month follow-up $(P<.09)$ and slightly higher than the 24-month results $(P<.031)$. Compared with baseline, mean VAS values dropped from 7.1 to 2.9 (Figure 2; a $59 \%$ improvement), and mean ODI values improved from 50 to 16 (Figure 3; a 68\% improvement). Both VAS and ODI scores surpassed the MCID values, from the first postoperative visit until the 84-month follow-up visit.

\section{Radiological Outcomes}

Table 2 summarizes the radiological parameters and end points. Average ROM values had statistically changed from a baseline of $12.0^{\circ}$ to $13.3^{\circ}$ at 12 months; however, they decreased to $9.9^{\circ}(P<.001)$

\section{Oswestry Disability Index}

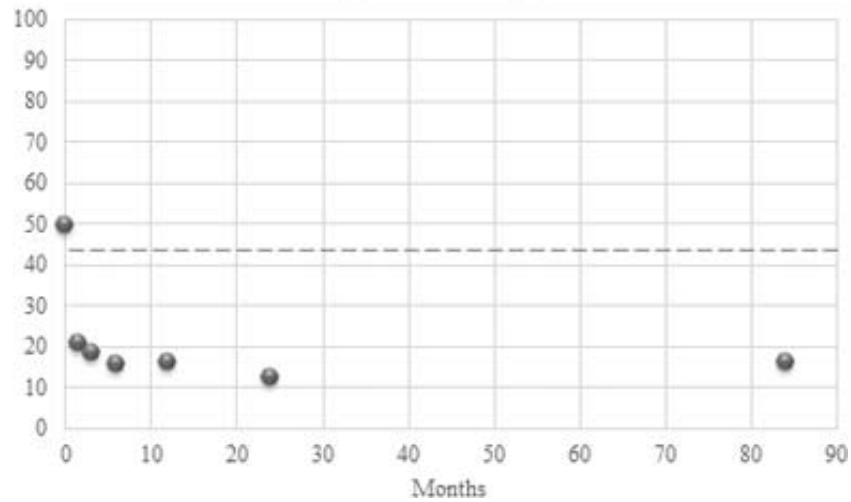

Figure 3. Physical disability assessed by Oswestry Disability Index. The plot shows mean values per follow-up visit. The dotted line represents the minimal clinically important difference value. All postoperative values are statistically different $(P<.001)$ from the 0 month point (preoperative). 
Table 2. Radiological outcomes at minimum 84-month follow-up.

\begin{tabular}{|c|c|c|c|c|c|c|c|c|c|}
\hline \multirow[b]{2}{*}{ Case No. } & \multirow[b]{2}{*}{ Level } & \multirow{2}{*}{\multicolumn{3}{|c|}{$\begin{array}{l}\text { Lordosis } \\
\text { (Internal } \\
\text { Prosthesis } \\
\text { End-Plate) }\end{array}$}} & \multirow{2}{*}{$\begin{array}{l}\text { Range of } \\
\text { Motion }\left({ }^{\circ}\right)\end{array}$} & \multirow[b]{2}{*}{ Radiolucency } & \multirow{2}{*}{$\begin{array}{l}\text { Adjacent-Level } \\
\text { Disease }\end{array}$} & \multirow{2}{*}{$\begin{array}{c}\text { Facet } \\
\text { Degeneration } \\
\text { (Hypertrophy/ } \\
\text { Narrowing) }\end{array}$} & \multirow{2}{*}{$\begin{array}{c}\text { Facet } \\
\text { Procedure }\end{array}$} \\
\hline & & & & & & & & & \\
\hline 1 & L5S1 & \multicolumn{8}{|c|}{ Revised at $62 \mathrm{mo}$ (TDR for ALD at $56 \mathrm{mo}$ ) } \\
\hline 2 & L5S1 & $\mathrm{n}$ & $\mathrm{n}$ & 13 & 8 & $\mathrm{n}$ & $\mathrm{n}$ & $\mathrm{n}$ & $\mathrm{n}$ \\
\hline 3 & L5S1 & $\mathrm{n}$ & $\mathrm{n}$ & 10 & 12 & $\mathrm{n}$ & $\mathrm{n}$ & $\mathrm{n}$ & $\mathrm{n}$ \\
\hline 4 & L5S1 & $\mathrm{n}$ & $\mathrm{n}$ & 8 & 6 & $\mathrm{n}$ & $\mathrm{n}$ & $\mathrm{y}$ & $\mathrm{n}$ \\
\hline 5 & L5S1 & $\mathrm{n}$ & $\mathrm{n}$ & 6 & 9 & $\mathrm{n}$ & $\mathrm{n}$ & $\mathrm{y}$ & $\mathrm{n}$ \\
\hline 6 & L5S1 & $\mathrm{n}$ & $\mathrm{n}$ & -1 & 4 & $\mathrm{n}$ & $\mathrm{n}$ & $\mathrm{n}$ & $\mathrm{n}$ \\
\hline 7 & L5S1 & $\mathrm{y}$ & $\mathrm{n}$ & 3 & 10 & $\mathrm{y}$ & $\mathrm{n}$ & $\mathrm{n}$ & $\mathrm{n}$ \\
\hline \multirow[t]{2}{*}{8} & L4L5 & $\mathrm{n}$ & $\mathrm{n}$ & 18 & 18 & $\mathrm{n}$ & $\mathrm{n}$ & $\mathrm{n}$ & $\mathrm{n}$ \\
\hline & L5S1 & $\mathrm{n}$ & $\mathrm{n}$ & 9 & 9 & $\mathrm{n}$ & & $\mathrm{n}$ & \\
\hline 9 & L5S1 & $\mathrm{n}$ & $\mathrm{n}$ & 7 & 11 & $\mathrm{n}$ & $\mathrm{n}$ & $\mathrm{y}$ & $\mathrm{n}$ \\
\hline 10 & L5S1 & \multicolumn{8}{|c|}{ Missed follow-up (last visit at $48 \mathrm{mo}$ ) } \\
\hline \multirow[t]{2}{*}{11} & L4L5 & \multicolumn{8}{|c|}{ Revised at 26 mo } \\
\hline & L5S1 & $\mathrm{n}$ & $\mathrm{n}$ & 7 & 10 & $\mathrm{n}$ & $\mathrm{n}$ & $\mathrm{y}$ & $\mathrm{n}$ \\
\hline 12 & L5S1 & \multicolumn{8}{|c|}{ Missed follow-up (last visit at $60 \mathrm{mo}$ ) } \\
\hline \multirow[t]{2}{*}{13} & L4L5 & $\mathrm{n}$ & $\mathrm{n}$ & -1 & 20 & $\mathrm{n}$ & $\mathrm{n}$ & $\mathrm{y}$ & $\mathrm{y}$ \\
\hline & L5S1 & $\mathrm{n}$ & $\mathrm{n}$ & 7 & 14 & $\mathrm{n}$ & & $\mathrm{y}$ & \\
\hline \multirow[t]{2}{*}{14} & L4L5 & $\mathrm{n}$ & $\mathrm{n}$ & 5 & 9 & $\mathrm{n}$ & $\mathrm{y}$ & $\mathrm{n}$ & $\mathrm{n}$ \\
\hline & L5S1 & $\mathrm{n}$ & $\mathrm{n}$ & -1 & 6 & $\mathrm{n}$ & & $\mathrm{y}$ & \\
\hline \multirow{2}{*}{15} & L3L4 & $\mathrm{n}$ & $\mathrm{n}$ & 8 & 8 & $\mathrm{n}$ & $\mathrm{n}$ & $\mathrm{n}$ & $\mathrm{n}$ \\
\hline & $\mathrm{L} 5 \mathrm{~S} 1$ & $\mathrm{n}$ & $\mathrm{n}$ & -5 & 5 & $\mathrm{n}$ & & $\mathrm{y}$ & \\
\hline Mean & & & & 5.8 & 9.9 & & & & \\
\hline $\mathrm{SD}$ & & & & 5.8 & 4.4 & & & & \\
\hline $95 \% \mathrm{CI}$ & & & & $2-10$ & $7-13$ & & & & \\
\hline
\end{tabular}

Abbreviations: TDR, total disc replacement; ALD, adjacent level disease; n, no; y, yes.

at the final evaluation. A typical case example is shown in Figure 4. Radiological progression of facet degeneration (hypertrophy and/or narrowing of the articular space) at index levels were present in 7 of the 15 levels with TDR (47\%). Although it was testified a radiological progression of facet degeneration, only one case $(9 \%$ of total cases, case no. 13, Figure 3) presented clinical symptoms related to this finding: facet pain due to instability at L4L5 at the last follow-up (7-year). This patient already presented an elevated range of motion before the surgery. Case No. 13 (Figure 5) is a double-level case (L4L5/L5S1) and presented L4L5 instability $\left(20^{\circ}\right.$ degrees of $\left.\mathrm{ROM}\right)$ and facet pain.

\section{Adverse Events and Revision}

In total, 4 cases had adverse events ( 3 two- and 1 one-level TDR). Three cases from 18 levels (16\%) needed some additional surgical intervention (one both ALD and TDR revision, one disc removal followed by interbody fusion, and one adjacent herniated nucleus pulposus removal). From the double-level cases, 3 of $5(60 \%)$ had adverse events, and from the 10 single-level cases, just 1 case $(10 \%)$ had adverse events.

Up to the final visit, 2 of 18 discs (11\%) required revision. One disc was revised and the other segment received instrumented posterolateral fusion. Figure
6 shows the prosthesis survival curve for patients who required disc revision or fusion of the index level. Case no. 11 (Figure 7) had a double-level TDR (L4L5 and L5S1), presented low back pain (painful motion) at the 2-year visit, had pain relief from L4L5 facet injections, and underwent prosthesis removal and interbody fusion. At 26 months the procedure was performed using a lateral transpsoas strategy, ${ }^{19-21}$ the disc was removed, and interbody fusion was completed according to subsequent imaging exams. The TDR at L5S1 from this patient was functional up to the 7-year follow-up; then this disc was included in the radiological analysis, but the case was not included the clinical outcomes. Case no. 1 with a L5S1 TDR presented painful instability at the adjacent level segment and had a TDR with a different prosthesis at L4L5 at the 56month follow-up point. After 6 months (62 months after Physio-L), this patient required posterior fusion and instrumentation at L5S1 and L4L5.

Two cases ( $13 \%$ of total cases) required surgical intervention due to ALD, case No. 1 at the 56month follow-up (due to DDD and treated with LTDR) and case no. 14 due to herniated nucleus pulposus. Case no. 14 is a double-level TDR (L4L5/ L5S1) and evolved with herniated nucleus pulposus (HNP) at the adjacent level (L3L4), requiring microdiscectomy at the 72-month follow-up window. 

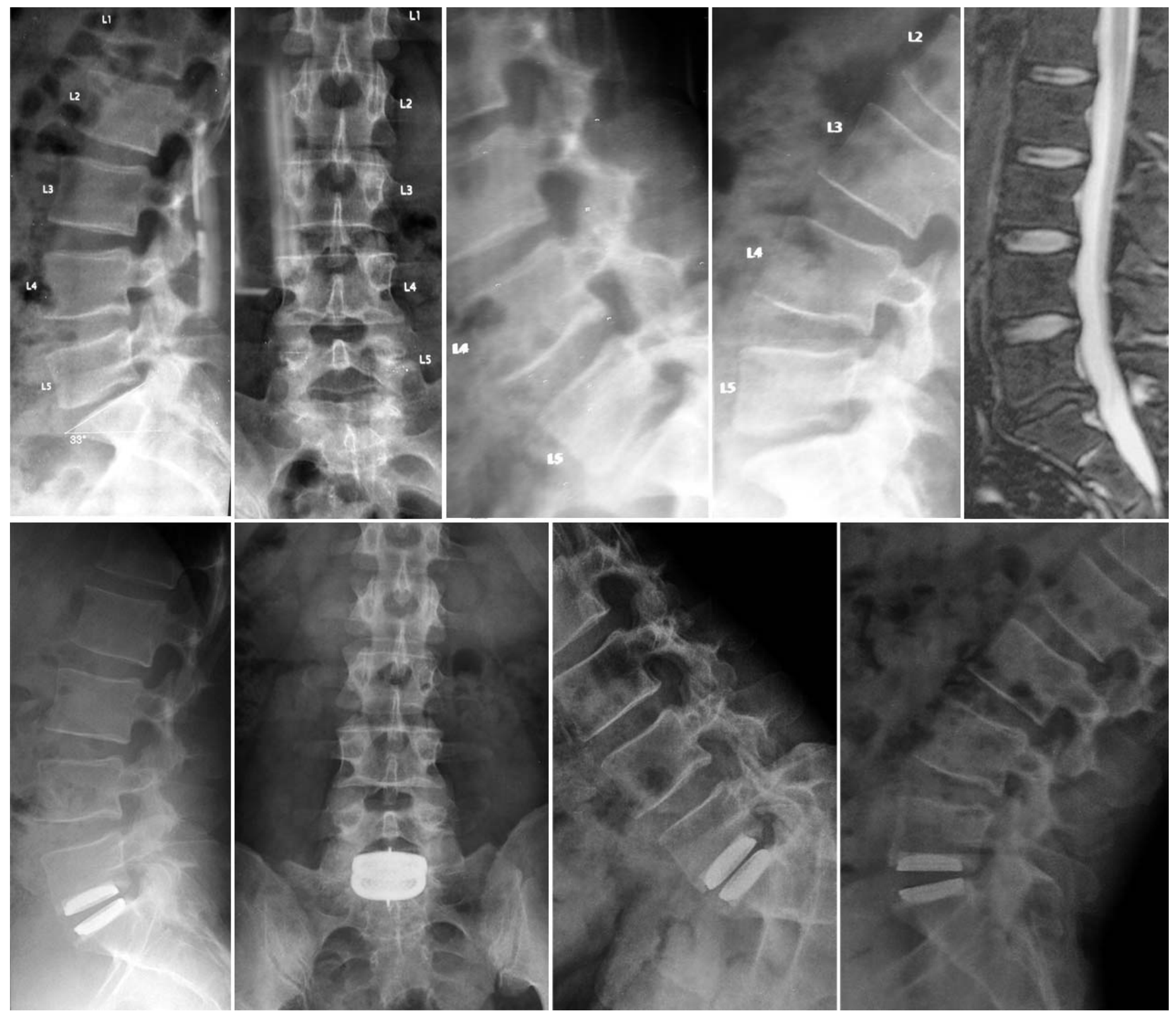

Figure 4. Case example of a typical L5S1 case. The first column shows preoperative x-rays (lateral neutral, antero-posterior, lateral flexion and extension) and sagittal magnetic resonance imaging images that evidence disc degeneration with dehydration, disc protrusion, disc and foramen height loss, without listhesis or other alignment alteration. Postoperative x-rays (lateral neutral, AP, lateral flexion and extension) in the bottom show disc and foramen height restoration, good alignment, and controlled motion.

In this series of cases there was no migration, dislocation, or breakage of the prosthesis observed. One minor subsidence was seen in a single-level case.

\section{DISCUSSION}

Chronic low back pain with or without radicular symptoms is an important condition that affects several people around the world ${ }^{22}$ and disc degeneration is one of the major risk factors. ${ }^{23}$ Despite the fact that conservative management is the first choice in the treatment strategy, unsuccessful nonsurgical care associated with clear degenerative radiological correlation can lead to an elective surgical procedure. Although fusion is the standard surgical method used to treat persistent low back pain caused by DDD, this option can have some important drawbacks such as the recovery time until complete bone fusion and also the biomechanical changes, which can accelerate degeneration at adjacent levels. ${ }^{24-26}$ TDR is a surgical option that aims to restore disc height, attenuate axial pain, and maintain movement in the operated level. By keeping the movement in the index level, this can reduce the chance of degeneration in the adjacent 


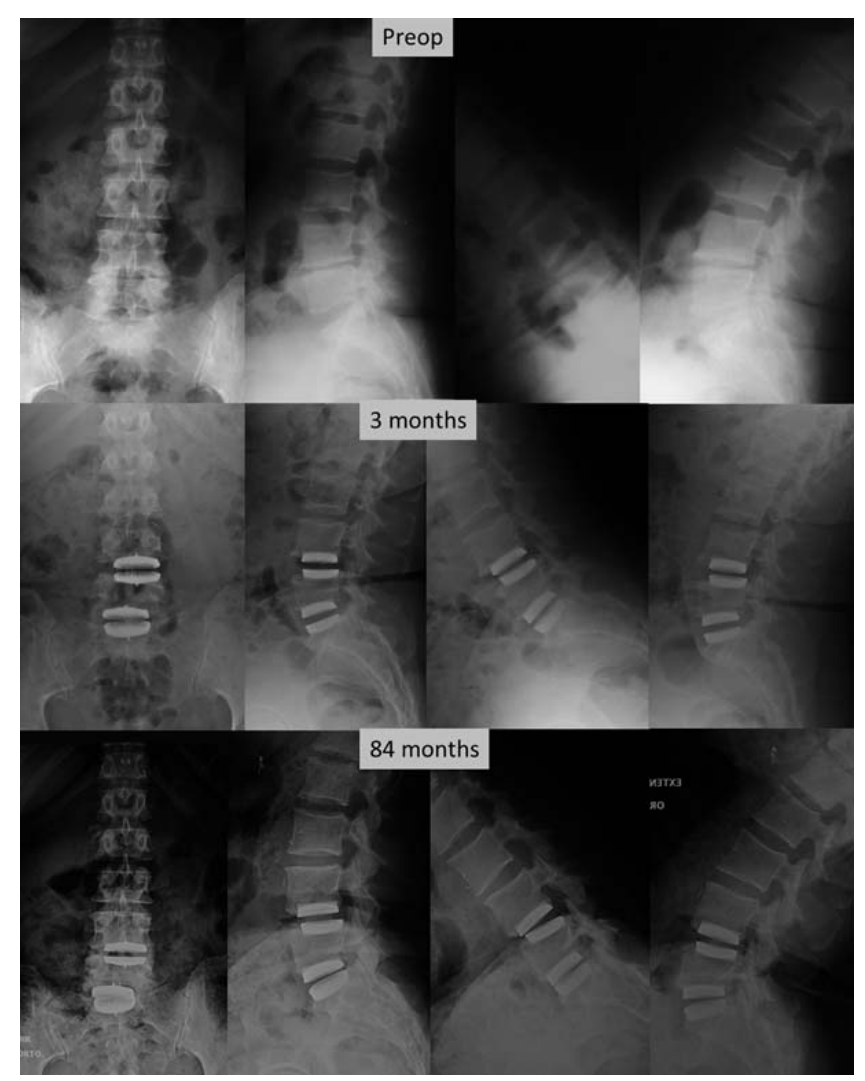

Figure 5. Example from a 2-level case that evolved with L4L5 facet pain at the last follow-up visit (case No. 13). X-rays (lateral neutral, antero-posterior, lateral flexion and extension) from different follow-up visits. Note that in the preoperative images, the L4L5 level already has a large range of motion, a sign that is still seen in the 84-month images.

levels. The aim of this study was to analyze the longterm radiological and clinical results of Physio- $\mathrm{L}$ TDR for degenerative conditions of the distal lumbar levels.

In this study, the clinical outcomes were assessed at 7 different visits. Results from pain assessments have shown that 7 years after disc replacement, the patients still experience around $60 \%$ improvement in comparison to the baseline level. The pain scores from the last visit were similar to the 12-month follow-up visit. However, these values from the last visit were slightly, but significantly, higher than the pain levels observed in the 24-month follow-up visit. Siepe et $\mathrm{al}^{27}$ followed 181 patients with ProDisc II arthroplasty, and they found a similar increase trend in VAS scores from 48 months to the final follow-up ( 7.4 years). This slight increase observed in the pain levels can be due to the progressive degenerative process of the spine elements, and this trend has already been observed in other modalities of surgical options for degenerative conditions of the spine. $^{28}$ The pain and disability scores improved, reaching the MCID from the postoperative until the

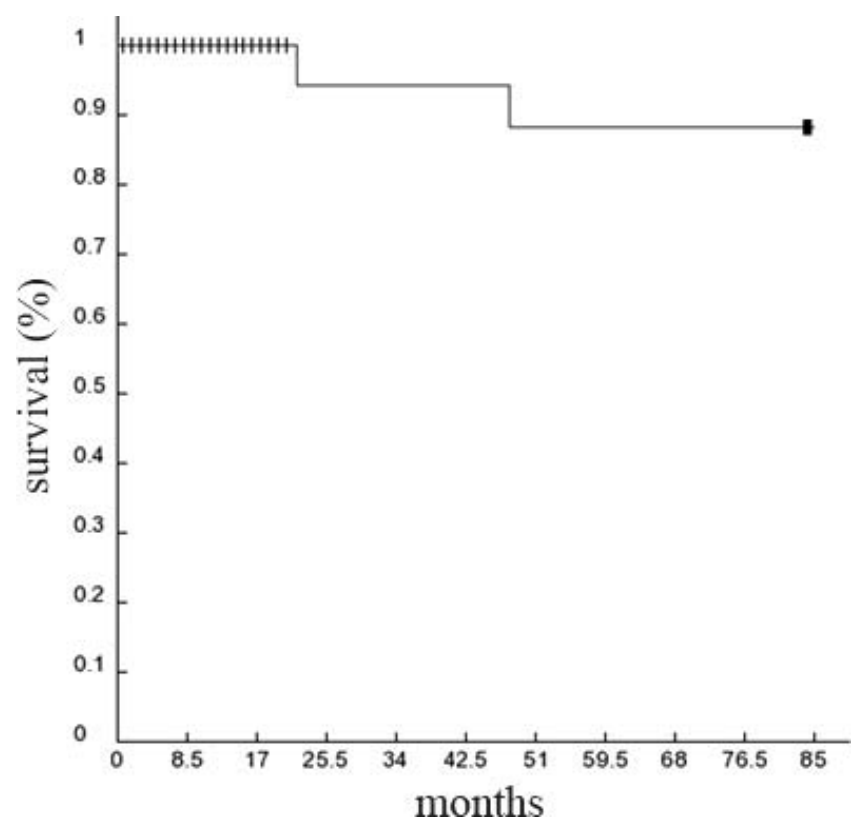

Figure 6. Prostheses survival curve. At 84-month follow-up, 16 of 18 prostheses ( $89 \%$ ) were still active ( 2 had fused, and 2 had missed the last follow-up).

84-month follow-up visit in comparison to the preoperative levels.

Another important outcome to evaluate is the stress on the adjacent levels and the incidence of degeneration in these levels. Although fusion is the most common option to treat degenerative disc conditions, it is implicated in high rates of adjacentlevel disease, around $14 \%$, according to a systematic review by Harrop et al. ${ }^{29}$ However, in the same study, ${ }^{29}$ they revealed an incidence about 14 times lower in arthroplasty when compared with fusion. In the current study, 2 out of 15 cases $(13 \%)$ experienced ALD, higher than other studies that analyzed mid- to long follow-up arthroplasty with other devices $(2 \%$ to $3 \%))^{8,27,30}$ Although the incidence of adjacent-level degeneration presented in this work appears to be discrepant with previous data from the literature, the number of participants in the present study is considerably lower than in others, revealing a limitation of our own.

Like other surgical procedures, TDR can have adverse events. Subsidence may be one important adverse event related to TDR. In the current study, no case of subsidence was observed in all 15 patients evaluated. Although Lu et $\mathrm{al}^{30}$ observed no symptomatic cases, $9.4 \%$ of the total cases operated upon with Charité III presented subsidence, different from the elastomeric core prosthesis presented here. Besides subsidence, a TDR can dislocate or migrate as time passes. In the same study, the authors 


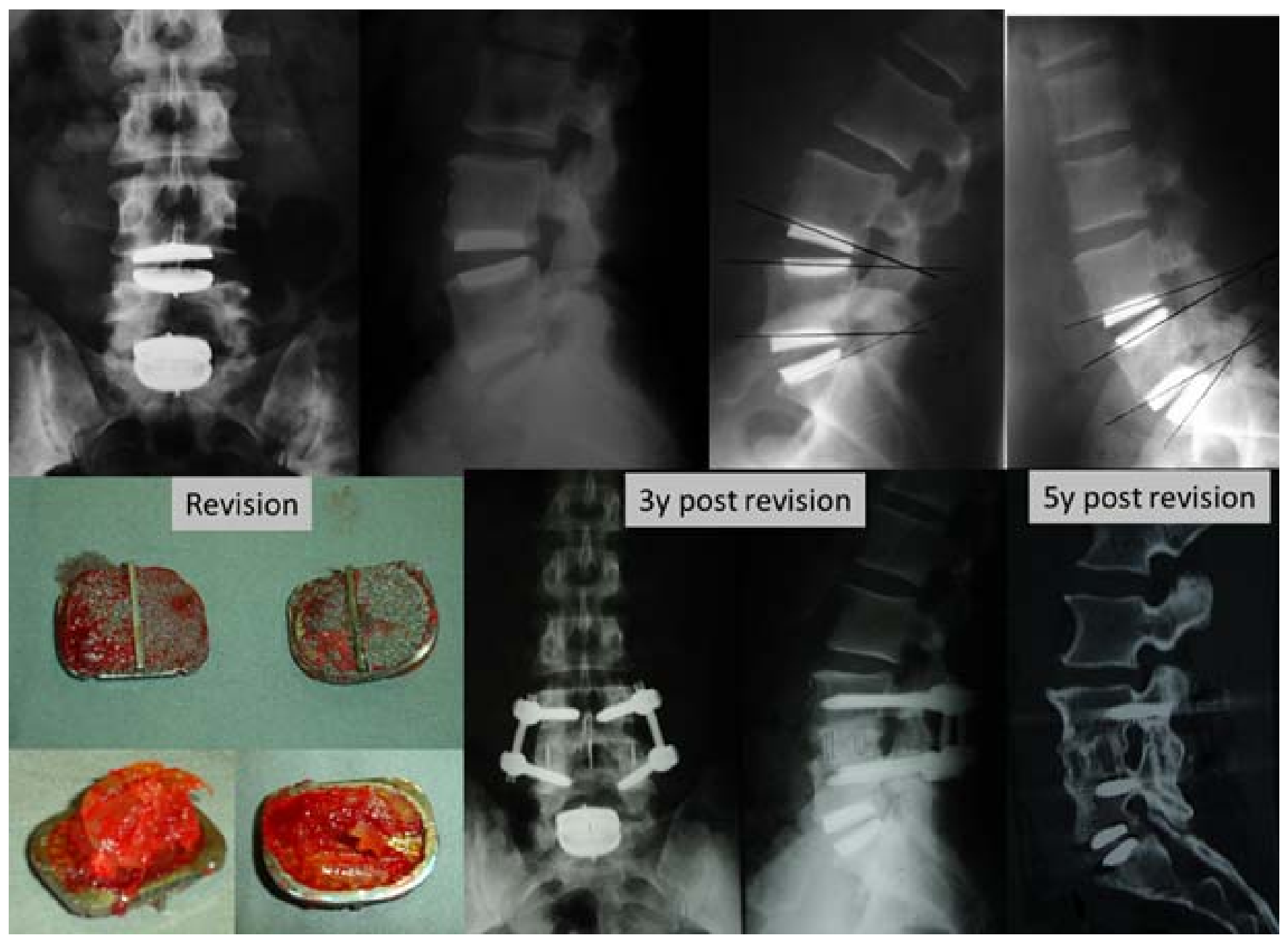

Figure 7. Case example that required disc removal (case no. 11). Patient evolved with low back pain (painful motion) at 2-year visit (x-ray images on top). Patient underwent revision of the L4L5 disc (bottom left images) followed by interbody fusion.

observed 15 cases of cage migration, from the milder grade to the most serious. ${ }^{30}$ The present study has not observed cases of migration or breakage, suggesting a superior implant condition when compared with Charité III. Although no adverse events directly related to the artificial disc were observed, $10 \%$ of the prostheses were removed, and $90 \%$ were active until the last follow-up visit.

Other pivotal parameters to evaluate in an artificial disc are the biomechanical properties. Given that the aim of the prosthesis is to mimic the function of a natural healthy disc, its ROM ideally must be as close as possible to a nonpathological disc. Average ROM values of the TDRs from the current study went from a baseline of $12.0^{\circ}$ to $13.3^{\circ}$ at 12 months, similar to values observed with a lateral artificial disc in a 36-month time point ${ }^{7}$ (which have a controlled motion due anterior longitudinal ligament [ALL] maintenance). ${ }^{31}$ Differently from a lateral disc, the vast majority of lumbar TRDs requires the removal of the ALL, the most important stabilizer ligament of the spine. ${ }^{7,34}$ Despite this, the average ROM values observed with Physio-L were not higher than preoperative values, with similar motion shortly after surgery and reduced motion at the last evaluation. This characteristic is due to the presence of the compressible polymer core, providing a more physiologic compliance, responsible for providing shock absorption, allowing the prosthesis to move in $6 d f$, providing controlled motion. ${ }^{33-36}$ This prosthesis differs from the first generation of prostheses such as Charité, which presents an increase in ROM and neutral zone in movement in all planes in comparison to the intact intervertebral disc. ${ }^{37}$ An increased motion in the segment can result in stress of the facet joints, increasing the possibility of facet degeneration in the long term. ${ }^{38}$ A study ${ }^{39}$ comparing Charite and ProDisc showed a similar incidence in a short follow-up (3 years), 
around $35 \%$ in total. In the short-term results of Physio-L (12 months), Pimenta et $\mathrm{al}^{34}$ have not reported facet degeneration, whereas the present study (minimum of 7 years follow-up) observed a $47 \%$ incidence of some level of radiological signs of facet degeneration at the final visit, but just $9 \%$ of total cases were symptomatic. The degeneration of the facets is part of the natural history of the degenerative condition, but a slower evolution would be reached by an arthroplasty strategy that could achieve the more physiologic compliance.

Although this work has good clinical and radiological outcomes, there are some limitations. This is a noncomparative retrospective study developed in a single center with a small sample. All limitations are inherent to the design of a feasibility study. Despite the limitations, this study reports a unique and long follow-up on the only elastomeric disc available for lumbar TDR.

\section{CONCLUSION}

This report shows results of a minimum of 84 months of follow-up of an elastomeric total disc replacement (Physio-L). In summary, TDR with Physio-L brought significant improvement in pain and disability scores and presented no migration or breakage of the prosthesis used. This long-term follow-up study shows that elastomeric TDR from the anterior approach may be an effective surgical option to treat DDD, especially for single-level conditions at L5S1, but more investigation with bigger cohorts must occur in order to better answer other questions regarding this prosthesis.

\section{REFERENCES}

1. Wang JC, Mummaneni PV, Haid RW. Current treatment strategies for the painful lumbar motion segment: posterolateral fusion versus interbody fusion. Spine. 2005;30(16 suppl):S33-S43.

2. Chan WCW, Au TYK, Tam V, Cheah KSE, Chan D. Coming together is a beginning: the making of an intervertebral disc. Birth Defects Res C Embryo Today. 2014;102(1):83-100.

3. Iorio JA, Jakoi AM, Singla A. Biomechanics of degenerative spinal disorders. Asian Spine J. 2016;10(2):377384.

4. Boos N, Weissbach S, Rohrbach H, Weiler C, Spratt $\mathrm{KF}$, Nerlich AG. Classification of age-related changes in lumbar intervertebral discs: 2002 Volvo Award in basic science. Spine. 2002;27(23):2631-2644.

5. Talia AJ, Wong ML, Lau HC, Kaye AH. Comparison of the different surgical approaches for lumbar interbody fusion. J Clin Neurosci. 2015;22(2):243-251.
6. Baliga S, Treon K, Craig NJA. Low back pain: current surgical approaches. Asian Spine J. 2015;9(4):645-657.

7. Marchi L, Oliveira L, Coutinho E, Pimenta L. The importance of the anterior longitudinal ligament in lumbar disc arthroplasty: 36-month follow-up experience in extreme lateral total disc replacement. Int J Spine Surg. 2012;6(1):18-23.

8. Rainey S, Blumenthal SL, Zigler JE, Guyer RD, Ohnmeiss DD. Analysis of adjacent segment reoperation after lumbar total disc replacement. Int J Spine Surg. 2012;1(6):140 144.

9. Pettine K, Hersh A. Kineflex lumbar artificial disc versus Charité lumbar total disc replacement for the treatment of degenerative disc disease: a randomized non-inferiority trial with minimum of 2 years' follow-up. SAS J. 2011;5(4):108-113.

10. Patrizzi LJ, Vilaça KHC, Takata ET, Trigueiro G. Preand post-surgery analysis of functional capacity and quality of life of patients with osteoarthritis submitted to total hip arthroplasty. Rev Bras Reumatol. 2004;44(3):185-191.

11. Borrego Paredes E, Barrena Sánchez P, Serrano Toledano D, Puente González AI, Fornell Pérez S, Domecq Fernández de Bobadilla G. Total knee arthroplasty after failed unicompartmental knee arthroplasty. Clinical results, radiologic findings, and technical tips. J Arthroplasty. 2017;32(1):193196.

12. Berg S, Tullberg T, Branth B, Olerud C, Tropp H. Total disc replacement compared to lumbar fusion: a randomised controlled trial with 2-year follow-up. Eur Spine $J$. 2009;18(10):1512-1519.

13. Zigler JE, Glenn J, Delamarter RB. Five-year adjacentlevel degenerative changes in patients with single-level disease treated using lumbar total disc replacement with ProDisc-L versus circumferential fusion. $J$ Neurosurg Spine. 2012;17(6):504-511.

14. Park CK. Total disc replacement in lumbar degenerative disc diseases. J Korean Neurosurg Soc. 2015;58(5):401-411.

15. Pfirrmann CW, Metzdorf A, Zanetti M, Hodler J, Boos N. Magnetic resonance classification of lumbar intervertebral disc degeneration. Spine. 2001;26(17):1873-1878.

16. Fujiwara A, Lim TH, An HS, et al. The effect of disc degeneration and facet joint osteoarthritis on the segmental flexibility of the lumbar spine. Spine. 2000;25(23):3036-3044.

17. Norman GR, Sloan JA, Wyrwich KW. Interpretation of changes in health-related quality of life: the remarkable universality of half a standard deviation. Med Care. 2003;41(5):582-592.

18. Copay AG, Subach BR, Glassman SD, Polly DW Jr, Schuler TC. Understanding the minimum clinically important difference: a review of concepts and methods. Spine $J$. 2007;7(5):541-546.

19. Bederman SS, Le VH, Pahlavan S, Kiester DP, Bhatia NN, Deviren V. Use of lateral access in the treatment of the revision spine patient. Sci World J. 2012;2012:1-6.

20. Pimenta L, Díaz RC, Guerrero LG. Charité lumbar artificial disc retrieval: use of a lateral minimally invasive technique. Technical note. J Neurosurg Spine. 2006;5(6):556561 .

21. Moisi M, Page J, Paulson D, Oskouian RJ. Technical note-lateral approach to the lumbar spine for the removal of interbody cages. Cureus. 2015;7(5):e268.

22. Vos T, Flaxman AD, Naghavi M, et al. Years lived with disability (YLDs) for 1160 sequelae of 289 diseases and 
injuries 1990-2010: a systematic analysis for the Global Burden of Disease Study 2010. Lancet. 2012;380(9859):2163-2196.

23. Mok FPS, Samartzis D, Karppinen J, Fong DYT, Luk KDK, Cheung KMC. Modic changes of the lumbar spine: prevalence, risk factors, and association with disc degeneration and low back pain in a large-scale population-based cohort. Spine J. 2016;16(1):32-41.

24. Park P, Garton HJ, Gala VC, Hoff JT, McGillicuddy JE. Adjacent segment disease after lumbar or lumbosacral fusion: review of the literature. Spine. 2004;29(17):1938-1944.

25. Lee JC, Kim Y, Soh J-W, Shin B-J. Risk factors of adjacent segment disease requiring surgery after lumbar spinal fusion: comparison of posterior lumbar interbody fusion and posterolateral fusion. Spine. 2014;39(5):E339-E345.

26. Ha K-Y, Son J-M, Im J-H, Oh I-S. Risk factors for adjacent segment degeneration after surgical correction of degenerative lumbar scoliosis. Indian $J$ Orthop. 2013;47(4):346-351.

27. Siepe CJ, Heider F, Wiechert K, Hitzl W, Ishak B, Mayer $\mathrm{MH}$. Mid- to long-term results of total lumbar disc replacement: a prospective analysis with 5- to 10-year followup. Spine J. 2014;14(8):1417-1431.

28. Videman T, Battié MC, Gibbons LE, Gill K. Aging changes in lumbar discs and vertebrae and their interaction: a 15-year follow-up study. Spine J. 2014;14(3):469-478.

29. Harrop JS, Youssef JA, Maltenfort M, et al. Lumbar adjacent segment degeneration and disease after arthrodesis and total disc arthroplasty. Spine. 2008;33(15):1701-1707.

30. Lu S-B, Hai Y, Kong C, et al. An 11-year minimum follow-up of the Charite III lumbar disc replacement for the treatment of symptomatic degenerative disc disease. Eur Spine J. 2015;24(9):2056-2064.

31. Pimenta L, Turner A, Oliveira L, Marchi L, Cornwall B. Controlled motion with the XL-TDR lateral-approach lumbar total disk replacement: in vitro kinematic investigation. J Neurol Surg A Cent Eur Neurosurg. 2015;76(2):133-138.

32. Panjabi MM, Goel VK, Takata K. Physiologic strains in the lumbar spinal ligaments. An in vitro biomechanical study 1981 Volvo Award in Biomechanics. Spine. 1982;7(3):192-203.

33. Lee CK. Development of an elastomeric total disc prosthesis (Physio-L). Paper presented at: 8th APSA Meeting; 2012; Seoul, Korea.

34. Pimenta L, Springmuller R, Lee CK, Oliveira L, Roth SE, Ogilvie WF. Clinical performance of an elastomeric lumbar disc replacement: minimum 12 months follow-up. SAS J. 2010;4(1):16-25.
35. Lazennec J-Y, Aaron A, Brusson A, Rakover J-P, Rousseau M-A. The LP-ESP lumbar disc prosthesis with 6 degrees of freedom: development and 7 years of clinical experience. Eur J Orthop Surg Traumatol. 2013;23(2):131-143.

36. Schätz C, Ritter-Lang $\mathrm{K}$, Gössel L, Dreßler N. Comparison of single-level and multiple-level outcomes of total disc arthroplasty: 24-month results. Int J Spine Surg. 2015;9:14.

37. Wilke H-J, Schmidt R, Richter M, Schmoelz W, Reichel H, Cakir B. The role of prosthesis design on segmental biomechanics. Eur Spine J. 2012;21(Suppl 5):577-584.

38. Huang RC, Girardi FP, Cammisa FP, Wright TM. The implications of constraint in lumbar total disc replacement. $J$ Spinal Disord Tech. 2003;16(4):412-417.

39. Shim CS, Lee S-H, Shin H-D, et al. CHARITE versus ProDisc: a comparative study of a minimum 3-year follow-up. Spine. 2007;32(9):1012-1018.

Disclosurse and COI: This work received support from the company involved in the manufacture of the device examined in this study. However, the data acquisition, including clinical data and the documentation of complication and reoperation rates, was exclusively performed by members of the medical group, including the principal investigator, members of the medical staff, and research assistants. The company/manufacturer had access to the data but had no influence on the results whatsoever.

Corresponding Author: Luiz Pimenta, Instituto de Patologia da Coluna, São Paulo, SP, Brazil. Phone: (+55) (11) 2936-8838; Email: j.nogueira@ patologiadacoluna.com.br.

Published 30 March 2018

This manuscript is generously published free of charge by ISASS, the International Society for the Advancement of Spine Surgery. Copyright (c) 2018 ISASS. To see more or order reprints or permissions, see http://ijssurgery.com. 